\title{
The screens culture: impact on ADHD
}

\author{
Margaret D. Weiss - Susan Baer - Blake A. Allan • \\ Kelly Saran $\cdot$ Heidi Schibuk
}

Received: 9 June 2011/Accepted: 5 September 2011 / Published online: 24 September 2011

(C) The Author(s) 2011. This article is published with open access at Springerlink.com

\begin{abstract}
Children's use of electronic media, including Internet and video gaming, has increased dramatically to an average in the general population of roughly $3 \mathrm{~h}$ per day. Some children cannot control their Internet use leading to increasing research on "internet addiction." The objective of this article is to review the research on ADHD as a risk factor for Internet addiction and gaming, its complications, and what research and methodological questions remain to be addressed. The literature search was done in PubMed and Psychinfo, as well as by hand. Previous research has demonstrated rates of Internet addiction as high as $25 \%$ in the population and that it is addiction more than time of use that is best correlated with psychopathology. Various studies confirm that psychiatric disorders, and ADHD in particular, are associated with overuse, with severity of ADHD specifically correlated with the amount of use. ADHD children may be vulnerable since these games operate in brief segments that are not attention demanding. In addition, they offer immediate rewards with a strong incentive to increase the reward by trying the next level. The time spent on these games may also exacerbate ADHD symptoms, if not directly then through the loss of time spent on more developmentally challenging tasks. While this is a major issue for many parents, there is no empirical research on effective treatment.
\end{abstract}

\footnotetext{
M. D. Weiss $(\square) \cdot$ S. Baer $\cdot$ K. Saran

Children's and Women's Health Centre of BC, University of British Columbia, 4500 Oak St., PO Box 178, Vancouver, BC V6H 3N1, Canada e-mail: mweiss@cw.bc.ca

B. A. Allan

University of Florida, Gainesville, FL, USA

H. Schibuk

McGill University, Montreal, QC, Canada
}

Internet and off-line gaming overuse and addiction are serious concerns for ADHD youth. Research is limited by the lack of measures for youth or parents, studies of children at risk, and studies of impact and treatment.

Keywords ADHD · Children · Computer use · Internet addiction $\cdot$ Gaming

\section{Introduction}

The past decade has seen an exponential growth in the use of Internet, video games, downloadable television, music and movies, and social networking (Media Awareness Network 2005; Smith et al. 2009). This change in our culture has had a marked impact on the development and daily activities of children. From a cognitive point of view, it has increased the use of visual relative to auditory communication and placed a premium on short snippets of communication rather than sentences and paragraphs. Where previously childhood consisted of free play in large group games, many children now live in a world of webbased media that may be foreign to many parents and even more alien to most grandparents. The emergence of this "screen culture" has been a paradigm shift in the world of childhood, and the implications of this bear some thought.

In 2008, the McCreary Centre Society (Smith et al. 2009), a non-government, nonprofit organization, provided research on screen time in the general adolescent population in Canada. Results indicated that on an average school day, $25 \%$ of youth spent upwards of $3 \mathrm{~h}$ watching TV and/or playing on the Internet and $15 \%$ played video games for more than $3 \mathrm{~h}$ (Smith et al. 2009). This is similar to another recent study of Canadian youth by Mark et al. showing average daily screen time of $3 \mathrm{~h} /$ day (Mark and Janssen 
2008). There is a suggestion that high-risk youth may spend even more time in front of screens, with a recent study showing daily screen time of almost $7 \mathrm{~h} /$ day in youth attending a psychiatric clinic (Baer et al. 2011). If the average child is spending one-third of their day on screen activities and high-risk children are spending most of their leisure hours on screens, risks and benefits must be evaluated from two points of view. First, what is the effect of this degree of exposure? Second, what is the effect of the loss of those activities that have been abandoned in its stead?

Concerns about overuse of these electronic tools have led to use of the term "internet addiction" (Byun et al. 2009). Various definitions for Internet addiction have been proposed based largely on criteria for substance abuse and impulse control disorders including compulsive gambling (Beard 2005; Demetrovics et al. 2008; Ko et al. 2005b; 2009c; Shaw and Black 2008; Tao et al. 2010; Fu et al. 2010). Proposed criteria focus on such factors as children's preoccupation with Internet activities, their inability to control their use, and their distress when use is limited. Continued use despite interference with other essential activities in children's lives such as learning, socializing, eating, or sleep is a key factor. There are marked differences of opinion between parents and children about whether Internet gaming is a good use of time, and differences between parents and children in ADHD research in general are endemic in the field. Concern about this phenomenon is widespread, with some arguing it should be included as a "disorder" for the Diagnostic and Statistical Manual V (Block 2008; Hinic et al. 2008; Kratzer and Hegerl 2008; Miller 2007; Pies 2009).

In 2006, Ha and colleagues did an early study that showed out of 455 children and 836 adolescents, $14 \%$ of children and $20 \%$ of adolescents screened positive for excessive Internet use (Ha et al. 2006). Similar studies reporting Internet addiction in children and youth have been reproduced around the world: in Korea (Cho et al. 2008; Park et al. 2008), Turkey (Ceyhan 2008), Taiwan (Lin and Yu 2008; Wan and Chiou 2006) Czechoslovakia (Simkova and Cincera 2004), Singapore (Mythily et al. 2008), Romania (Chirita et al. 2006), Italy (Coniglio et al. 2007; Ferraro et al. 2007), Iran (Ghassemzadeh et al. 2008), Greece (Siomos et al. 2008), Norway (Johansson and Gotestam 2004), and China (Song et al. 2010; Xu et al. 2008). Reported rates of addiction typically range between 2 and $20 \%$ with some reporting as high as $25 \%$ (Zboralski et al. 2009). A comparative study found significantly higher rates of Internet addiction in China than the United States, suggesting cultural factors may play a role (Jackson et al. 2008). Baer et al. have shown that the presence of addictive features is correlated with psychopathology and functional impairment, whereas as screen time in the absence of addiction is not (Baer et al. 2011).
ADHD is well known to impart an increased risk of substance abuse disorders (Cumyn et al. 2009; Ohlmeier et al. 2007, 2008) as well as impulse control disorders such as compulsive gambling (Lawrence et al. 2009). This raises the question whether children with ADHD are more at risk of overuse of the Internet or off-line gaming.

Parents frequently complain about their children spending excessive amounts of time on gaming and the difficulty they experience in getting their child to comply with turning off the game. Children who are not otherwise oppositional may experience extreme rages if a parent pulls the plug in the middle of a game when a child is noncompliant with instructions to turn it off. Parents present clinicians with many questions: "How much time on the computer is reasonable?" "How can I get my child to learn how to turn the computer off?" "If he is on the computer all the time, he's not playing with other children or playing sports, is this a problem?" While some guidelines on "screen time" have been created (AAP 2001), clinicians are typically left to rely on their personal opinions in answering many of these questions.

The objective of this article is to review the research on the relationship between use of the Internet and nonInternet-based (off-line) video gaming with ADHD. This review will address several issues. What research has been done to determine whether ADHD is a risk factor for increased time in front of the computer or gaming station? If so, what do we know about ADHD that might make these children more vulnerable? Is there any suggestion that Internet and gaming may worsen or improve ADHD core symptoms? We will review what has been written about the treatment for overuse of Internet and gaming activities or "internet addiction." Finally, we will summarize what is known to date, methodological limitations in the research, and possible areas of future study.

\section{The relationship between ADHD, the Internet, and off-line video gaming}

While most of the studies on Internet use are cross-sectional, one recent prospective study followed over 2,000 adolescents for 2 years to determine whether the presence of psychiatric symptoms would predict later development of Internet addiction (Ko et al. 2009b). While depression and social phobia were also associated with later problems (particularly in girls), ADHD was shown to be the most significant predictor for the development of Internet addiction, followed by hostility, after controlling for sex and age. Looking at gender groups separately, hostility was the strongest predictor in boys and ADHD was the strongest predictor for girls. 
This prospective study is consistent with results from several cross-sectional studies looking at the association between ADHD symptoms and Internet addiction (Chan and Rabinowitz 2006; Ha et al. 2006; Yen et al. 2007, 2009; Yoo et al. 2004). Yen et al. found that ADHD symptoms correlated with Internet addiction in a sample of over 2,500 college students (Yen et al. 2009). The strongest association was seen in female students, similar to the results in the Ko et al. prospective study. Similar associations have been found in younger age groups as well, with Yoo et al. showing higher ADHD symptoms in elementary students with Internet addiction (Yoo et al. 2004). Associations between ADHD and Internet addiction have also been shown in the adolescent population with Yen et al. reporting higher levels of ADHD, depression, and hostility in boys with Internet addiction, and higher levels of ADHD and depression in girls with Internet addiction (Yen et al. 2007). Chan et al. have noted a correlation between severity of ADHD symptoms (particularly inattention) and time spent on the Internet (Chan and Rabinowitz 2006).

ADHD traits such as impulsivity (Cao and Su 2007; Cao et al. 2007), extraversion (Mottram and Fleming 2009), disinhibition (Sun et al. 2009), and low self-esteem (Niemz et al. 2005) correlate with Internet use and abuse. One small study directly compared video game playing in children with ADHD versus controls (Bioulac et al. 2008). Interestingly, there was no difference in frequency or duration of video game play between the two groups. However, the children with ADHD showed higher levels of addiction than controls, suggesting that it is not time so much as the capacity for use to become more driven and problematic that differentiates Internet use in ADHD compared to the general population.

Further evidence for a connection between ADHD and Internet use is found in a provocative treatment study by Han et al. looking at the effect of methylphenidate treatment on video game play (Han et al. 2009). In this study, 62 drug-naïve children with ADHD and Internet addiction were treated with 8 weeks of methylphenidate. Along with reduction in ADHD symptoms, both Internet usage times and scores on Internet addiction tests were shown to decrease over the treatment period.

In summary, there is a growing body of evidence for an association between problematic Internet and off-line video gaming use and ADHD. While other psychiatric symptoms such as depression and anxiety have also been shown to be associated with Internet addiction (Chak and Leung 2004; Ryu et al. 2004; Shapira et al. 2000), the Ko et al. prospective study shows that ADHD is the strongest predictor (Ko et al. 2009b). This begs the question, why? What is it about children with ADHD that makes them particularly vulnerable to overuse of the Internet and off-line gaming?
ADHD youth may have a predisposed vulnerability to the immediacy of feedback as well as the multimodal and high stimulation nature of games. Most games are built so that there is an incentive to "get to the next level," which has an immediacy that makes it a particularly salient reward incentive to ADHD patients. In addition, rapidly changing screens put minimal demands on attention and working memory (Van De Voorde et al. 2010), forced effort, or writing (Adi-Japha et al. 2007) all of which are difficult in ADHD. Individuals with ADHD tend to seek enhanced stimulation of the reward pathway (Volkow et al. 2009). Video gaming has been shown to increase striatal dopamine release (Koepp et al. 1998) activating this reward pathway. Further evidence for this hypothesis is found in a study by Han et al., which showed youth with Internet addiction had higher reward dependency and increased prevalence of specific polymorphisms of the dopamine receptor gene implicated in alcoholism and pathologic gambling, when compared with normal controls (Han et al. 2007). There is no research that has examined whether Internet addiction in youth is associated with increased risk for Internet gambling in adulthood, but assuming that Internet addiction is comparable to other addictions, one might anticipate that childhood exposure may be a gateway to more serious problematic Internet use in adulthood such as pornography or gambling.

ADHD symptoms and Internet or gaming addiction may share a bidirectional relationship where the symptoms of ADHD make gaming attractive, while gaming itself exacerbates ADHD symptoms by providing an activity that continuously reinforces the exact disinhibition, quick responsiveness, need for immediate reward, and inattention that are areas of concern. In this sense, the prolonged hours of Internet and gaming use may further reinforce and consolidate the child's proclivity to impulsive, rapid, hyper-focused reactivity. This is also in contrast to the types of activity that might have otherwise filled the same leisure hours such as complex play, sports, music and arts, or organized youth clubs, which would help develop attention, self-control, behavioral inhibition, self-discipline, team skills, and socialization. Even if Internet addiction is not responsible for worsening ADHD symptoms, lack of exposure to these activities might be associated with a decrease in practice opportunities for working memory, patience, attention, and executive functioning (Diamond 2007; Diamond et al. 2007). There are then several pathways that might explain the bidirectional association between Internet addiction and ADHD.

Risks and benefits of video gaming

Children may feel proud of the level they have achieved in a particular game. There are now Internet games available 
in which children can play online with their friends and use a headset to interact by voice while playing. Parents often perceive their child's perseverative video gaming as a sign of good attention and frequently report their children as having higher than average gaming skills. There is, in fact, research that suggests that some forms of computer gaming may build attentional and visual spatial skills (Green and Bavelier 2003). This raises the question as to whether there may be some skill-building benefit to video gaming in children with ADHD. It is possible that some games will augment reading skills, if reading is required, or fine motor coordination. Computer programs have been developed to improve working memory (Klingberg et al. 2005), but this does not necessarily apply to recreational games that were not designed for this purpose. In fact, in controlled studies, ADHD is as much an impairment to recreational video gaming as it is to most areas of functioning (Lawrence et al. 2002, 2004), with children with ADHD performing more poorly on video games than controls. Thus, parental perception that gaming is what their child does well is likely based more by comparison with their difficulties in many other areas. Other research, however, has demonstrated that children with ADHD, who demonstrated specific problems with impulsive responding on a standardized measure, did not show the same difficulty on a more gamelike task, indicating that video games may be a context in which inhibitory performance is consistently reinforced since it is required in most games (Shaw et al. 2005).

The risks of Internet use and gaming have been investigated in terms of correlations between use and negative outcomes such as obesity, aggression, and poor school outcome (Mark and Janssen 2008; Ko et al. 2009d). The limitation of all such studies is that they are based on correlations and do not establish cause. The children studied are at risk for many of these problems already and so the correlation may reflect an attribute of the population rather than problematic Internet use or games.

Treatment for "internet addiction"

Although excessive use of the Internet and off-line gaming has been demonstrated to be a common, problematic and global problem, the lack of a standardized definition and assessment measures for Internet addiction limits treatment information. As stated in a recent review by Weinstein and colleagues, "Due to the lack of methodologically adequate research, it is currently impossible to recommend any evidence-based treatment of Internet addiction" (Weinstein and Lejoyeux 2010). There are reports of treatment trials reporting success using many different treatment modalities. Most focus on CBT and CBT groups (Pujol Cda et al. 2009; Young 2007), whereas others have looked at a multilevel counseling program (Orzack and Orzack 1999;
Shek et al. 2009), pharmacotherapy (Dell'Osso et al. 2008; Han et al. 2009), empowerment education (Joo and Park 2010), abstinence (Kalke and Raschke 2004), and family therapy with ongoing counseling and follow-up along the model of alcoholics anonymous (Orzack and Orzack 1999). While these reports suggest that Internet addiction may be treatable, we have no research to suggest which treatment is most effective, and no randomized controlled trials to demonstrate that any of these treatments have been effective. Furthermore, we have no guidelines for advising families what risks and benefits typical use carries, or guidelines for how much time should be spent in media that to parents may seem "a waste of time," but for children reflects the way their peer group relates.

\section{Limitations of the literature}

The literature on Internet and off-line video gaming addiction is riddled with methodological problems, several of which have been outlined in recent reviews (Abreu et al. 2008; Byun et al. 2009; Weinstein and Lejoyeux 2010). All of the research described above is based on the use of selfreport measures designed for adults and used in youth. This raises a serious concern, since this is something like asking an alcoholic how much he drinks - in any addiction, there is a tendency to minimize the problem.

There is no current accepted definition for Internet addiction (although many have been proposed (Beard 2005; Demetrovics et al. 2008; Fu et al. 2010; Ko et al. 2005b, 2009c; Shaw and Black 2008; Tao et al. 2010) making comparison between studies difficult. Different studies focus on different activities, with most focusing exclusively on Internet use, not including off-line computer and gaming station use, which is common in children who tend to do a wide variety of these activities. There is little work on excessive texting, which is now extremely common. With the exception of one prospective study (Ko et al. 2009b) and the study by Lam and Peng (2010) studies are limited to correlations, which do not address causality.

In addition, terminology varies between studies. Multiple measures have been used to assess Internet and gaming addiction (Beard 2005; Davis et al. 2002; Demetrovics et al. 2008; Johansson and Gotestam 2004; Khazaal et al. 2008; Ko et al. 2005a; Meerkerk et al. 2009; Nichols and Nicki 2004; Tejeiro Salguero and Bersabe Moran 2002). Many of these scales focus exclusively on Internet use. One scale looks exclusively at video gaming (either on or offline) (Tejeiro Salguero and Bersabe Moran 2002). Much of the research on Internet addiction has taken place in Asia, and some of the most widely used measures, e.g., the Chen Internet Addiction Scale (Ko et al. 2009c, 2005a), are not available in English translation. One of the most widely used English language measures, the Internet Addiction 
Test (IAT) (Young 1998a, b) has only been validated in adults (Chang and Law 2008; Widyanto and McMurran 2004) and includes questions that are inappropriate for children. One validation study included some youth, but mean age of the sample was just over 25 (Widyanto and McMurran 2004). Furthermore, in developing an Internet and games abuse scale for youth, one would have to be wary of child self-report that might underestimate time spent, such that a parent version would also be needed. Since such a scale has an obvious halo effect, it would be helpful to embed the questions in a more neutral information gathering context.

Finally, there is little research looking at positive effects of Internet use. For example, a child with selective mutism may be able to "chat." A child with social phobia may begin the process of meeting people. Even in the area of ADHD, children who are rejected and cannot handle the complexity of social cues may do very well in conversations that rely on a delay and online conversation. Lastly, the obvious potential of these media for teaching has just begun to be explored.

\section{Summary}

This review of the literature suggests that there is a correlation between Internet and off-line video gaming use and psychiatric disorders, particularly ADHD. While the condition of "internet addiction" remains controversial (Shaffer et al. 2000), the consensus of the global literature to date, is that Internet addiction is a disorder in its own right, and that for those who are vulnerable it presents a serious risk with demonstrable impairment and increased psychiatric symptomatology. It remains unclear whether the Internet use itself is the causal factor for increasing psychiatric symptoms and impairment or a simply a reflection of underlying difficulties. We additionally do not yet know whether there is a potential for these media to improve the lives of children, for example by opening up new avenues of learning or increasing opportunities for socialization. However, the evidence presented in this review makes a strong case for a connection between ADHD and Internet, and off-line video gaming use, suggesting that the clinician assessing children with ADHD should routinely inquire about these activities. Stronger conclusions await better definitions of terms such as "internet addiction" and the development of standardized, validated assessment measures for youth. We are in immediate need of systematic research into the etiology of the relationship of computer use and abuse and ADHD, its risks, possible benefits, and treatments. Specifically, future research is required to determine whether there is increased engagement in social and developmentally enriching activities when screen time is decreased; a cohort study of ADHD children versus normal controls for total screen time and further exploration of measurement of the relationship between screen time and functional impairment. We need the answers to the questions every parent is asking.

Key Points:

1. Recreational electronic activities including Internet use and off-line gaming have become normative in youth, with a mean of roughly $3 \mathrm{~h}$ per day in the general population, and over $6 \mathrm{~h}$ per day in the psychiatric population.

2. Youth with mental illness are particularly vulnerable to Internet addiction and overuse, with ADHD being the most common risk factor.

3. The impact of this screen culture on child development and on the trajectory of mental illness in youth needs investigation, particularly given the resulting loss of time spent in other developmentally necessary activities.

4. The impact of screen abuse on ADHD core symptoms and oppositional defiant disorder is unknown.

5. Despite parents raising this issue and seeking guidance from mental health practitioners, there are no randomized controlled trials on treatment for Internet addiction.

Open Access This article is distributed under the terms of the Creative Commons Attribution Noncommercial License which permits any noncommercial use, distribution, and reproduction in any medium, provided the original author(s) and source are credited.

\section{References}

AAP (2001) American academy of pediatrics: children, adolescents, and television. Pediatrics 107(2):423-426

Abreu CN, Karam RG, Goes DS, Spritzer DT (2008) Internet and videogame addiction: a review. Rev Bras Psiquiatr 30(2): $156-167$

Adi-Japha E, Landau YE, Frenkel L, Teicher M, Gross-Tsur V, Shalev RS (2007) ADHD and dysgraphia: underlying mechanisms. Cortex 43(6):700-709

Baer S, Bogusz E, Green DA (2011) Stuck on screens: patterns of computer and gaming station use in youth seen in a psychiatry clinic. J Can Acad Child Adolesc Psychiatry 20(2):86-94

Beard KW (2005) Internet addiction: a review of current assessment techniques and potential assessment questions. Cyberpsychol Behav 8(1):7-14

Bioulac S, Arfi L, Bouvar MP (2008) Attention deficit/hyperactivity disorder and video games: a comparative study of hyperactive and control children. Eur Psychiatry 23(2):134-141

Block JJ (2008) Issues for DSM-V: internet addiction. Am J Psychiatry 165(3):306-307

Byun S, Ruffine C, Mills JE, Douglas AC, Niang M, Stepchenkova S, Lee SK, Loutfi J, Lee J-K, Atallah M, Blanton M (2009) Internet addiction: metasynthesis of 1996-2006 quantitative research. Cyberpsychol Behav 12(2):203-207 
Cao F, Su L (2007) Internet addiction among Chinese adolescents: prevalence and psychological features. Child Care Health Dev 33(3):275-281

Cao F, Su L, Liu T, Gao X (2007) The relationship between impulsivity and internet addiction in a sample of Chinese adolescents. Eur Psychiatry 22(7):466-471

Ceyhan AA (2008) Predictors of problematic internet use on Turkish university students. Cyberpsychol Behav 11(3):363-366. doi: $10.1089 / \mathrm{cpb} .2007 .0112$

Chak K, Leung L (2004) Shyness and locus of control as predictors of internet addiction and internet use. Cyberpsychol Behav 7(5): 559-570

Chan PA, Rabinowitz T (2006) A cross-sectional analysis of video games and attention deficit hyperactivity disorder symptoms in adolescents. Ann Gen Psychiatry 5:16

Chang MK, Law SPM (2008) Factor structure for young's internet addiction test: a confimatory study. Comput Human Behav 24(6):2597-2619

Chirita V, Chirita R, Stefanescu C, Chele G, Ilinca M (2006) Computer use and addiction in Romanian children and teenagers-an observational study. Rev Med Chir Soc Med Nat Iasi 110(3):526-532

Cho SC, Kim JW, Kim BN, Lee JH, Kim EH (2008) Biogenetic temperament and character profiles and attention deficit hyperactivity disorder symptoms in Korean adolescents with problematic internet use. Cyberpsychol Behav 11(6):735-737

Coniglio MA, Muni V, Giammanco G, Pignato S (2007) Excessive Internet use and internet addiction: emerging public health issues. Ig Sanita Pubbl 63(2):127-136

Cumyn L, French L, Hechtman L (2009) Comorbidity in adults with attention-deficit hyperactivity disorder. Can J Psychiatry 54(10): 673-683

Davis RA, Flett GL, Besser A (2002) Validation of a new scale for measuring problematic internet use: implications for preemployment screening. Cyberpsychol Behav 5(4):331-345

Dell'Osso B, Hadley S, Allen A, Baker B, Chaplin WF, Hollander E (2008) Escitalopram in the treatment of impulsive-compulsive internet usage disorder: an open-label trial followed by a doubleblind discontinuation phase. J Clin Psychiatry 69(3):452-456

Demetrovics Z, Szeredi B, Rozsa S (2008) The three-factor model of internet addiction: the development of the problematic internet use questionnaire. Behav Res Methods 40(2):563-574

Diamond A (2007) Consequences of variations in genes that affect dopamine in prefrontal cortex. Cereb Cortex 17(Suppl 1): i161-i170

Diamond A, Barnett WS, Thomas J, Munro S (2007) Preschool program improves cognitive control. Science 318(5855):13871388

Ferraro G, Caci B, D’Amico A, Di Blasi M (2007) Internet addiction disorder: an Italian study. Cyberpsychol Behav 10(2):170-175

Fu KW, Chan WS, Wong PW, Yip PS (2010) Internet addiction: prevalence, discriminant validity and correlates among adolescents in Hong Kong. Br J Psychiatry 196(6):486-492

Ghassemzadeh L, Shahraray M, Moradi A (2008) Prevalence of internet addiction and comparison of internet addicts and nonaddicts in Iranian high schools. Cyberpsychol Behav 11(6): 731-733

Green CS, Bavelier D (2003) Action video game modifies visual selective attention. Nature 423:534-537

Ha JH, Yoo HJ, Cho IH, Chin B, Shin D, Kim JH (2006) Psychiatric comorbidity assessed in Korean children and adolescents who screen positive for internet addiction. J Clin Psychiatry 67(5): $821-826$

Han DH, Young SL, Yang KC, Kim EY, Lyoo IK, Renshaw PF (2007) Dopamine genes and reward dependence in adolescents with excessive internet video game play. J Addict Med 1(3): $133-138$

Han DH, Lee YS, Na C, Ahn JY, Chung US, Daniels MA, Haws CA, Renshaw PF (2009) The effect of methylphenidate on internet video game play in children with attention-deficit/hyperactivity disorder. Compr Psychiatry 50(3):251-256

Hinic D, Mihajlovic G, Spiric Z, Dukic-Dejanovic S, Jovanovic M (2008) Excessive internet use-addiction disorder or not? Vojnosanit Pregl 65(10):763-767

Jackson LA, Zhao Y, Qiu W, Kolenic A, Fitzgerald HE III, Harold R, Von Eye A (2008) Cultural differences in morality in the real and virtual worlds: a comparison of Chinese and US youth. Cyberpsychol Behav 11(3):279-286. doi:10.1089/cpb.2007.0098

Johansson A, Gotestam KG (2004) Internet addiction: characteristics of a questionnaire and prevalence in Norwegian youth (12-18 years). Scand J Psychol 45(3):223-229

Joo A, Park I (2010) Effects of an empowerment education program in the prevention of internet games addiction in middle school students. J Korean Acad Nurs 40(2):255-263

Kalke J, Raschke P (2004) Learning by doing: 'initiated abstinence', a school-based programme for the prevention of addiction. Results of an evaluation study. Eur Addict Res 10(2):88-94

Khazaal Y, Billieux J, Thorens G, Khan R, Louati Y, Scarlatti E, Theintz F, Lederrey J, Van Der Linden M, Zullino D (2008) French validation of the internet addiction test. Cyberpsychol Behav 11(6):703-706

Klingberg T, Fernell E, Olesen PJ, Johnson M, Gustafsson P, Dahlstrom K, Gillberg CG, Forssberg H, Westerberg H (2005) Computerized training of working memory in children with ADHD - a randomized, controlled trial. J Am Acad Child Adolesc Psychiatry 44(2):177-186

Ko C-H, Yen J-Y, Yen C-F, Chen C-C, Yen C-N, Chen S-H (2005a) Screening for internet addiction: an empirical study on cut-off points for the Chen Internet Addiction Scale. Kaohsiung J Med Sci 21(12):545-551

Ko CH, Yen J-Y, Chen C-C, Chen S-H, Yen C-F (2005b) Proposed diagnostic criteria of internet addiction for adolescents. J Nerv Ment Dis 193(11):728-733

Ko CH, Liu GC, Hsiao S, Yen JY, Yang MJ, Lin WC, Yen CF, Chen CS (2009a) Brain activities associated with gaming urge of online gaming addiction. J Psychiatr Res 43(7):739-747

Ko CH, Yen JY, Chen CS, Yeh YC, Yen CF (2009b) Predictive values of psychiatric symptoms for internet addiction in adolescents: a 2 year prospective study. Arch Pediatr Adolesc Med 163(10):937-943

Ko CH, Yen JY, Chen SH, Yang MJ, Lin HC, Yen CF (2009c) Proposed diagnostic criteria and the screening and diagnosing tool of internet addiction in college students. Compr Psychiatry 50(4):378-384

Ko CH, Yen JY, Liu SC, Huang CF, Yen CF (2009d) The associations between aggressive behaviors and internet addiction and online activities in adolescents. J Adolesc Health 44(6): 598-605

Koepp MJ, Gunn RN, Lawrence AD, Cunningham VJ, Dagher A, Jones T, Brooks DJ, Bench CJ, Grasby PM (1998) Evidence for striatal dopamine release during a video game. Nature 393: 266-268

Kratzer S, Hegerl U (2008) Is "internet addiction" a disorder of its own?-a study on subjects with excessive internet use. Psychiatr Prax 35(2):80-83

Lam LT, Peng ZW (2010) Effect of pathological use of the internet on adolescent mental health: a prospective study. Arch Pediatr Adolesc Med 164(10):901-906

Lawrence V, Houghton S, Tannock R, Douglas G, Durkin K, Whiting K (2002) ADHD outside the laboratory: boys' excutive function 
performance on tasks in videogame play and on a visit to the zoo. J Abnorm Child Psychol 30(5):447-462

Lawrence V, Houghton S, Douglas G, Durkin K, Whiting K, Tannock $R$ (2004) Executive function and ADHD: a comparison of children's performance during neuropsychological testing and real-world activities. J Atten Disord 7(3):137-149

Lawrence AJ, Luty J, Bogdan NA, Sahakian BJ, Clark L (2009) Problem gamblers share deficits in impulsive decision-making with alcohol-dependent individuals. Addiction 104(6):10061015

Lin $\mathrm{CH}, \mathrm{Yu}$ SF (2008) Adolescent internet usage in Taiwan: exploring gender differences. Adolescence 43(170):317-331

Mark AE, Janssen I (2008) Relationship between screen time and metabolic syndrome in adolescents. J Public Health 30(2): $153-160$

Media Awareness Network (2005) Media Awareness Network: young Canadians in a Wired World-Phase II http://www.media-aware ness.ca/english/research/YCWW/phaseII/upload/YCWWII_trends_ recomm.pdf. Accessed April 92010

Meerkerk GJ, Van Den Eijnden RJ, Vermulst AA, Garretsen HF (2009) The compulsive internet use scale (CIUS): some psychometric properties. Cyberpsychol Behav 12(1):1-6. doi: $10.1089 / \mathrm{cpb} .2008 .0181$

Miller MC (2007) Questions \& answers. Is "internet addiction" a distinct mental disorder? Harv Ment Health Lett 24(4):8

Mottram AJ, Fleming MJ (2009) Extraversion, impulsivity, and online group membership as predictors of problematic internet use. Cyberpsychol Behav 12(3):319-321

Mythily S, Qiu S, Winslow M (2008) Prevalence and correlates of excessive internet use among youth in Singapore. Ann Acad Med Singap 37(1):9-14

Nichols LA, Nicki R (2004) Development of a psychometrically sound internet addiction scale: a preliminary step. Psychol Addict Behav 18(4):381-384

Niemz K, Griffiths M, Banyard P (2005) Prevalence of pathological internet use among university students and correlations with selfesteem, the general health questionnaire (GHQ), and disinhibition. Cyberpsychol Behav 8(6):562-570

Ohlmeier MD, Peters K, Kordon A, Seifert J, Wildt BT, Wiese B, Ziegenbein M, Emrich HM, Schneider U (2007) Nicotine and alcohol dependence in patients with comorbid attention-deficit/ hyperactivity disorder (ADHD). Alcohol Alcohol 42(6): 539-543

Ohlmeier MD, Peters K, Te Wildt BT, Zedler M, Ziegenbein M, Wiese B, Emrich HM, Schneider U (2008) Comorbidity of alcohol and substance dependence with attention-deficit/hyperactivity disorder (ADHD). Alcohol Alcohol 43(3):300-304

Orzack MH, Orzack DS (1999) Treatment of computer addicts with complex co-morbid psychiatric disorders. Cyberpsychol Behav 2(5):465-473

Park SK, Kim JY, Cho CB (2008) Prevalence of internet addiction and correlations with family factors among South Korean adolescents. Adolescence 43(172):895-909

Pies R (2009) Should DSM-V designate "internet addiction" a mental disorder? Psychiatry Edgmont 6(2):31-37

Pujol Cda C, Alexandre S, Sokolovsky A, Karam RG, Spritzer DT (2009) Internet addiction: perspectives on cognitive-behavioral therapy. Rev Bras Psiquiatr 31(2):185-186

Ryu E-J, Choi K-S, Seo J-S, Nam B-W (2004) The relationships of Internet addiction, depression and suicidal ideation in adolescents. Daehan Ganho Haghoeji 34(1):102-110

Shaffer HJ, Hall MN, Vander Bilt J (2000) "Computer addiction": a critical consideration. Am J Orthopsychiatry 70(2):162-168

Shapira NA, Goldsmith TD, Keck PE, Kholsa UM, McElroy SL (2000) Psychiatric features of individuals with problematic internet use. J Affect Dis 57:267-272
Shaw M, Black DW (2008) Internet addiction: definition, assessment, epidemiology and clinical management. CNS Drugs 22(5): $353-365$

Shaw R, Grayson A, Lewis V (2005) Inhibition, ADHD, and computer games: the inhibitory performance of children with ADHD on computerized tasks and games. J Attention Dis 8(4): $160-168$

Shek DT, Tang VM, Lo CY (2009) Evaluation of an internet addiction treatment program for Chinese adolescents in Hong Kong. Adolescence 44(174):359-373

Simkova B, Cincera J (2004) Internet addiction disorder and chatting in the Czech Republic. Cyberpsychol Behav 7(5):536-539

Siomos KE, Dafouli ED, Braimiotis DA, Mouzas OD, Angelopoulos NV (2008) Internet addiction among Greek adolescent students. Cyberpsychol Behav 11(6):653-657

Smith A, Stewart D, Peled M, Poon C, Saewyc E (2009) A picture of health: highlights from the 2008 BC Adolescent Health Survey. McCreary Centre Society, Vancouver

Song XQ, Zheng L, Li Y, Yu DX, Wang ZZ (2010) Status of 'internet addiction disorder' (IAD) and its risk factors among first-grade junior students in Wuhan. Zhonghua Liu Xing Bing Xue Za Zhi 31(1):14-17

Sun DL, Chen ZJ, Ma N, Zhang XC, Fu XM, Zhang DR (2009) Decision-making and prepotent response inhibition functions in excessive internet users. CNS Spectr 14(2):75-81

Tao R, Huang X, Wang J, Zhang H, Zhang Y, Li M (2010) Proposed diagnostic criteria for internet addiction. Addiction 105(3): $556-564$

Tejeiro Salguero RA, Bersabe Moran RM (2002) Measuring problem video game playing in adolescents. Addiction 97:1601-1606

Van De Voorde S, Roeyers H, Verte S, Wiersema JR (2010) Working memory, response inhibition, and within-subject variability in children with attention-deficit/hyperactivity disorder or reading disorder. J Clin Exp Neuropsychol 32(4):366-379

Volkow ND, Wang GJ, Kollins SH, Wigal TL, Newcorn JH, Telang F, Fowler JS, Zhu W, Logan J, Ma Y, Pradhan K, Wong C, Swanson JM (2009) Evaluating dopamine reward pathway in ADHD: clinical implications. JAMA 302(10):1084-1091

Wan CS, Chiou WB (2006) Why are adolescents addicted to online gaming? an interview study in Taiwan. Cyberpsychol Behav 9(6):762-766. doi:10.1089/cpb.2006.9.762

Weinstein A, Lejoyeux M (2010) Internet addiction or excessive internet use. Am J Drug Alcohol Abuse 36(5):277-283. doi: $10.3109 / 00952990.2010 .491880$

Widyanto L, McMurran M (2004) The psychometric properties of the internet addiction test. Cyberpsychol Behav 7(4): $443-450$

Xu J, Shen LX, Yan CH, Wu ZQ, Ma ZZ, Jin XM, Shen XM (2008) Internet addiction among Shanghai adolescents: prevalence and epidemiological features. Zhonghua Yu Fang Yi Xue Za Zhi 42(10):735-738

Yen JY, Ko CH, Yen CF, Wu HY, Yang MJ (2007) The comorbid psychiatric symptoms of internet addiction: attention deficit and hyperactivity disorder (ADHD), depression, social phobia, and hostility. J Adolesc Health 41(1):93-98

Yen JY, Yen CF, Chen CS, Tang TC, Ko CH (2009) The association between adult ADHD symptoms and internet addiction among college students: the gender difference. Cyberpsychol Behav 12(2):187-191

Yoo HJ, Cho SC, Ha J, Yune SK, Kim SJ, Hwang J, Chung A, Sung YH, Lyoo IK (2004) Attention deficit hyperactivity symptoms and internet addiction. Psychiatry Clin Neurosci 58(5):487-494

Young KS (1998a) Caught in the net: how to recognize signs of internet addiction-and a winning strategy for recovery. Wiley, New York 
Young KS (1998b) Internet addiction: the emergence of a new clinical disorder. Cyberpsychol Behav 1(3):237-244

Young KS (2007) Cognitive behavior therapy with internet addicts: treatment outcomes and implications. Cyberpsychol Behav 10(5):671-679
Zboralski K, Orzechowska A, Talarowska M, Darmosz A, Janiak A, Janiak M, Florkowski A, Galecki P (2009) The prevalence of computer and internet addiction among pupils. Postepy Hig Med Dosw (Online) 63:8-12 